\title{
Os intermúndios literários de Monteiro Lobato e Godofredo Rangel em A Barca de Gleyre
}

\section{Ana Luiza Reis Bedê}

Resumo As sartas de Monteiro Lobato a Godofredo Rangel, inseridas em A Barca de Gleyre, constituem uma biografia intelectual do autor de Urupês. Podem também ser lidas como espaço privilegiado de criação, pois trazem reflexōes estéticas e críticas sobre obras nacionais e estrangeiras. Palavras-chave Monteiro Lobato; Godofredo Rangel; A Barca de Gleyre.

Abstract The letters from Monteiro Lobato to Godofredo Rangel, inserted in A Barca de Gleyre, constitute an intellectual biography of the author of Urupês. They may also be read as a privileged space of creation, since they bring about esthetic reflections and critics on Brazilian and foreign books. Keywords Monteiro Lobato; Godofredo Rangel; A Barca de Gleyre. 
Só de você espero ocasionalmente algum lubrificante. Literariamente, vivo pendurado em você, como quem caiu num abismo e se agarrou a uma raiz. Se você me larga, vou ao fundo.

[Monteiro Lobato a Godofredo Rangel, 27/09/1910]

A Barca de Gleyre reúne as cartas de Monteiro Lobato endereçadas a Godofredo Rangel entre 1903 e 1948. Se Lobato dispensa apresentação, seu correspondente é hoje pouco conhecido. José Godofredo de Moura Rangel nasceu em 21 de novembro de 1884 em Três Corações (MG) e faleceu em Belo Horizonte em 1951. Cursou Direito em São Paulo na Faculdade do Largo São Francisco. Durante sua estada na capital paulista, alugou uma casa na rua 21 de Abril, no Belenzinho. Como de sua sacada descortinava-se uma bela vista, o poeta Ricardo Gonçalves comparou-a à torre de uma mesquita; daí o nome "Minarete", o ponto de encontro de Monteiro Lobato, Godofredo Rangel, Ricardo Gonçalves, Cândido Negreiros, Raul de Freitas, Tito Lívio Brasil, Lino Moreira e José Antônio Nogueira. Esse grupo autodenominava-se "Cenáculo". Reunia-se no "Minarete" ou no café Guarany, no Largo do Rosário, para discutir filosofia e literatura. Rangel publicou os romances Os bem casados (1910), Falange gloriosa (1917), Vida ociosa (1921), além das coletâneas de contos Andorinhas (1921) e Os humildes (1944).

Em 9 de dezembro de 1903, o estudante de Direito Monteiro Lobato escreve ao amigo Godofredo Rangel: "Sigo logo para a fazenda e quero de lá corresponderme contigo longa e minuciosamente, em cartas intermináveis - mas é coisa que só farei se me convencer de que queres realmente semelhante coisa"."

Assim, por iniciativa de Lobato, inicia-se com ares de projeto essa longa palestra epistolar. Logo nessa primeira carta, o signatário cobra de seu correspondente a mesma vontade de manter um vínculo. $O$ futuro escritor paulista queria continuar,

1 Utilizamos a edição: LOBATO, Monteiro. A Barca de Gleyre. Quarenta anos de correspondência literária entre

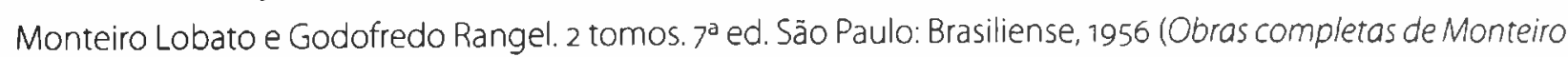
Lobato, v. 11 e v. 12). A Barca de Gleyre contempla um conjunto de 339 cartas de Lobato, enviadas de Sāo Paulo, Areias, Taubaté, da fazenda Buquira, Caçapava, Santos, Rio de Janeiro e Nova lorque; não foram localizadas até a presente data as missivas assinadas por Rangel. 
à distância, a rica troca intelectual que desfrutou com Rangel entre 1900 e 1903, ano em que este terminara seu curso na Faculdade do Largo São Francisco e, enquanto aguardava uma nomeação para juiz, lecionava português no interior de Minas.

A partir de então, por mais de quarenta anos, a correspondência versará sobre os mais diversos assuntos, desde ambições profissionais de ambos até questões políticas e problemas socioeconômicos do interior paulista. A incansável campanha de Lobato pela exploração do ferro e do petróleo e sua prisão, em 1941, pelo Estado Novo, são relatadas ao companheiro. Notícias dos amigos dos bons tempos de estudante vinham à tona com a natural franqueza que essa conversa secreta permitia. Assuntos domésticos e problemas afetivos recheiam as missivas.

O tema principal, porém, e razão mesma da correspondência, é a literatura. Os correspondentes questionam o real valor dos textos que produziam, expõem as dúvidas, trocam impressões. Lobato e Rangel sugerem leituras, emprestando livros um ao outro. Há um incentivo mútuo para escrever, sempre com compromisso de apontar as falhas. De fato, se essa correspondência vingou, foi graças à paixão, da parte de ambos, pela literatura, e ao desejo, ou melhor, projeto acalentado durante anos e, por fim, levado a cabo, apesar do halo pessimista que envolve a obra: tornarem-se, um dia, escritores.

Quando, em 1916, Rangel sugere levar a público a correspondência, Lobato, a princípio, descarta a hipótese, em carta de 17 de março: "O que essas minhas cartas pedem é fósforo. Toca-lhes fogo e pronto. Quanta pretensão lá dentro". O escritor mineiro, convencido da qualidade das cartas, insiste no assunto e, em 29 de outubro, recebe a resposta agora trazendo o interesse do amigo pela documentação: "Chegas a insistir na absurda ideia da publicação! Estou curioso de relê-las e verificar que enxertos são esses tão do teu agrado."

As cartas do ano de 1916 revelam como a ideia de publicar começa a tomar corpo, mas somente em 1943 Rangel acaba por convencer o amigo, que, em 27 de outubro desse ano, reconhece que o conjunto das missivas assumiria o status de "obra":

Já tenho todas as cartas passadas a máquina e estou a lê-las de cabo a rabo. Noto muita unidade. Verdadeiras memórias dum novo gênero - escritas a intervalos e sem nem por sombras a menor ideia de que um dia fossem publicadas. Que pedantismo o meu no começo! Topete incrível. Emília pura [...]. 
Nesse mesmo ano, Edgard Cavalheiro recebe das mãos do próprio autor o valioso conjunto das cartas e responsabiliza-se por sua edição em 1944.

Por sugestão de Monteiro Lobato, o livro tem o nome inspirado em tela de Charles Gleyre, pintor de origem suíça (1808-1874), que reproduz um barco partindo do cais, sendo observado por um velho ao lado de uma lira. Na missiva de 15 de novembro de 1904, Lobato compara o destino dos dois ao da melancólica personagem do quadro: "O teu artigo me evocou a barca do velho. Em que estado voltaremos, Rangel, desta nossa aventura de arte pelos mares da vida em fora?"

Formação da consciência artística Nas páginas de $A$ Barca de Gleyre, podemos rastrear concepções artísticas e a busca de Lobato por um estilo. Testemunhamos a angústia de sua incessante procura de uma feição que fugisse às regras impostas por tendências estéticas conhecidas.

Quanto às obras lidas e que estão na base de suas reflexões, podemos dizer que sua curiosidade ia dos clássicos da literatura universal às produções brasileiras. Acompanhava atento o que se passava na França, conforme era comum, então, entre os letrados. Contudo, procurava enriquecer-se com tais leituras e não se dobrar em humilde veneração.

A concepção de arte em Monteiro Lobato delineia-se ao longo de quase toda a correspondência. A missiva de 15 de novembro de 1904 constitui verdadeiro programa estético:

Estamos moços e dentro da barca. Vamos partir. O que é a nossa lira? Um instrumento que temos de apurar, de modo que fique mais sensivel que o galvanômetro, mais penetrante que o microscópio: a lira eólia do nosso senso estético. Saber sentir, saber ver, saber dizer. E tem você de rangelizar a tua lira, e o Edgard tem que edgardizar a dele, e eu de lobatizar a minha. Inconfundibiliza-las. Nada de imitar seja lá quem for, Eça ou Ésquilo. Ser um Eça II ou um Ésquilo III, ou um sub-Eça, um sub-Ésquilo, sujeiras! Temos de ser nós mesmos, apurar os nossos Eus, formar o Rangel, o Edgard, o Lobato. Ser núcleo de cometa, não cauda. Puxar fila, não seguir. 
Lobato procura um rumo para construir sua obra, mas quer evitar sendas trilhadas. Via a produção literária do Brasil com pessimismo, pois julgava que os escritores da literatura dita oficial conformavam-se ainda em "seguir", bem comportados, as estéticas vigentes na Europa. Lobato coloca-se na contramão da moda, seja dos naturalistas tardios, seja dos parnasianos. Essa aversão às ideias importadas explicaria, em parte, a sua não-adesão à Semana de 22.

Ainda nessa missiva, acrescenta:

Há no mundo o ódio à exceção - e ser si mesmo é ser exceção. Ser exceção e defendê-la contra todos os assaltos da uniformização: isto me parece a grande coisa. Se a tomarmos como programa, é possível que um dia apanhemos a borboleta de asas de fogo - e não tem a mínima importância que nos queime as mãos e a nossa volta seja como a do velho de Gleyre.

O compromisso assumido em lobatizar constitui ideia fixa do autor de Urupês. Essa preocupação em “inconfundibilizar” o estilo estendia-se a Rangel. Lobato com frequência adverte o amigo sobre a admiração que este nutria por Gustave Flaubert e Eça de Queirós. Era necessário desvencilhar-se dessas influências (ao menos da forma como Rangel submetia-se a elas), pois denunciavam falta de confiança em si mesmo. Lobato irritava-se tanto com a pouca ambição monetária do autor de Vida ociosa quanto com a sua modéstia. Em carta de 7 de julho de 1907, ao comentar uma personagem criada por Rangel, alerta: "Que importa o meu parecer? Que importa o parecer de alguém? Quem tem talento e arte impõe-nos ao mundo - não pede licenças".

A importância atribuída à sinceridade nas opiniões emitidas vislumbra-se em vários momentos da correspondência. Para que ambos crescessem como artistas, precisariam comprometer-se a dizer tudo o que pensavam ao outro. Não havia espaço para circunlóquios ou eufemismos. Esse acordo tácito era um dos aspectos que contribuíam para a formação do senso estético. Lobato acreditava também que este ia aperfeiçoando-se involuntariamente através de um tipo de "sedimentação geológica", construída através de sucessivas leituras, e, a partir destas, cada um formava sua própria visão do mundo. Em carta de 10 de janeiro de 1904, afirma: 
Tua carta é um atestado de tua doença: literatura errada. Julgas que para ser um homem de letras vitorioso faz-se mister uma obsessão constante, uma consciente martelação na mesma ideia - e a mim a coisa me parece diferente. Tenho que o bom é que as aquisições sejam inconscientes, num processo de sedimentação geológica. Qualquer coisa que cresça por si, como as árvores, apenas arrastada por aquilo que Aristóteles chamava enteléquia - e que em você é o rangelismo e em mim é o lobatismo.

Além da "enteléquia", da filosofia aristotélica que implicava a realização de uma potencialidade natural, Lobato absorve de Nietzsche a ideia de "sedimentação geológica". Inspirou-se em Nietzsche, cuja obra causou grande impacto no meio literário em todo o mundo no começo do século xx. No Brasil, Assim falou Zaratustra teve uma recepção ruidosa, como nos explica Brito Broca, ${ }^{2}$ e era citação obrigatória. Em Monteiro Lobato, as premissas do autor de Assim falou Zaratustra proporcionaram o topete filosófico do qual extraiu as bases de sua poética. Em 1904, indica um projeto literário a Rangel:

[...] só conheço um que te sirva: rangelizar-te sempre e cada vez mais. Escreve em tua porta isto da Gaya Scienza de Nietzsche: vademecum-vadetecum. Mon allure et mon langage t'attirent, tu viens sur mes pas, tu veux me suivre? Suis-toi même fidèlement.

As ideias do filósofo alemão representaram para Lobato o "pólen". Fascinava-o tudo que despertava o homem para sua própria descoberta. Trata-se de uma teoria que aposta na força do indivíduo e vai ao encontro da aversão de Lobato ao "toda gente" e à "vulgaridade".

Percebe-se, ao longo de suas missivas, que a autoconfiança de Monteiro Lobato, sua crença no próprio talento, na própria inteligência, bem como sua coragem de sustentar as próprias opiniões em qualquer circunstância e a despeito de qualquer moda revelam a sua faceta "nietzschiana" e situam-no como o verdadeiro pontade-lança dos anos de 1910.

2 BROCA, Brito. Vida literária no Brasil 1900. Rio de Janeiro: José Olympio, 1960, p. 189. 
Espaço de experimentação Maurice Blanchot comenta as duas formas segundo as quais os críticos costumam analisar as cartas de um escritor. Há uma tentativa de confirmar o discurso do autor tanto do ponto de vista biográfico quanto do ponto de vista estético; nesse segundo caso, a correspondência serviria para explicar a obra fictícia. Embora sejam abordagens pertinentes, o texto é convocado somente pelo valor informativo. ${ }^{3}$

$\mathrm{Na}$ verdade, nem sempre as cartas de escritores interessam ao pesquisador de literatura. Isso se explica quando as missivas enfocam sobretudo assuntos do cotidiano, com uma linguagem essencialmente referencial, despojada de interesse estético. Afinal, a função precípua da carta consiste em estabelecer um elo de comunicação. Paralelamente, cartas escritas por pessoas comuns podem muitas vezes apresentar um grau de "literariedade" para empregar uma expressão dos formalistas russos, que lhes confere valor artístico.

No caso de Lobato, sua correspondência com Lima Barreto decepciona o pesquisador, porque, com exceção de poucos comentários sobre a obra de ambos ou de terceiros, as cartas tratam, na maior parte das vezes, de questões comerciais. Lobato, além de convidar Lima Barreto a colaborar na Revista do Brasil, editou o romance Vida e morte de M. J. Gonzaga de Sá em 1919.

Em A Barca de Gleyre, ao contrário, a carta representa mais do que veículo de comunicação e de discussões críticas. A missiva oferece a Lobato a liberdade de criar novos vocábulos e desrespeitar as regras gramaticais; afinal, como afirmou em carta de 7 de novembro de 1904: "Língua de cartas é língua em mangas de camisa e pé no chão como a falada". Dono de uma inteligência ágil e penetrante, fazia saborosos jogos de palavras e criava neologismos tanto a partir de nomes comuns quanto de próprios. Por exemplo: maupassanadas; maupassanescos; tartarinescos (relativo a Tartarin de Tarascon); flaubertite; ecite (relativo a Eça de Queirós); zolaiamos; zefernandear (Zé Fernandes era o diretor da escola onde Rangel lecionou português); rangelizar, edgardizar, fala em estilo assimfalouzaratustra.

Quanto aos neologismos formados de nomes comuns e de verbos, lemos: desempoeiramento; trombeteamento; andejismo; telecaceteando; cenaculoides; achavascadamente; literatizo; magisterdixismo; luademelar; atitudismo; antitudista; etc....

3 Apud GRASSI Marie-Claire. Lire lépistolaire. Paris: Dunod, 1998, p. 161.

136 - BEDÊ, Ana Luiza Reis. Os intermúndios literários de Monteiro Lobato... 
Vale aqui abrir um pequeno parêntese para assinalar um ponto comum com Mme. de Sévigné (a autora é citada en passant em carta de 11 de fevereiro de 1926) que, com sua linguagem natural e espirituosa, inventava palavras ou as transformava. Criou neologismos inspirados em nomes próprios como "rabutiner", referência às conversas com o primo e também escritor Bussy-Rabutin; "lavardiner" significava bavarder com Mme. de Lavardin. Mme. de Sévigné nutria um incondicional prazer pelo escrever e não se furtava a fazer jogos de palavras: "Il ne tient pas à moi que je ne voie Mme. de Valavoire. Il est vrai qu' il n' est pas besoin de me dire: "Va la voir"" 4

Apontamos esse detalhe comum entre as cartas da célebre missivista do século XVII francês e de nosso autor para salientar a relevância da correspondência como espaço de experimentaçāo. ${ }^{5}$ Este aspecto relativo ao poder criador e de violaçāo das normas já justificaria um estudo sobre as missivas de Lobato a Rangel.

Em sua obra de ficção, tais recursos são empregados de forma mais econômica. A linguagem original e criativa das cartas de Lobato contribui, assim, para cedermos a elas o direito de cidadania nos estudos literários. A correspondência do autor de Negrinha representa mais que um interessante conjunto de dados biográficos e históricos, sendo, na verdade, um manancial expressivo do ponto de vista temático (sugestões) e formal (experimentos linguísticos).

Lobato vislumbra as possibilidades literárias da carta, ao se dirigir a Rangel em 30 de setembro de 1915:

Já notaste como é mais vivo o estilo das cartas, do que o de tudo quanto visa aparecer em livro ou jornal? Acho maravilhoso o prime saut das cartas. Eu queria ver em todos os teus livros o elance primesautier da última carta que me mandaste. A caraça do público, a "feição" do jornal, os moldes do editor, sempre antepostos aos nossos olhos quando "escrevemos para imprimir" acanham-nos a expressão, destroem-nos a alerteza do élan. Eu, por mim, só lia cartas e memórias como as do Casanova.

\footnotetext{
4 Ibidem, p. 76.

5 Sobre o prazer da escrita e o humor em Madame Sévigné, v. AMARAL, Glória Carneiro do. "Sévigné em ação: sévignações". In: GALVĀO, Walnice Nogueira; GOTLIB, Nádia Battella (Orgs.). In: Prezado senhor, Prezada senhora: estudo sobre cartas. São Paulo: Companhia das Letras, 2000, p. 19-33.
} 
A expressão primesautier, grifada por Lobato, significa "qui se détermine, agit, parle spontanément" (Petit Robert) e foi empregada mais de uma vez nas cartas, a fim de indicar a ausência de artifícios por parte de algum autor. Por que não empregaria simplesmente o nosso "espontâneo"? Talvez pela sonoridade do vocábulo francês que evocaria a ideia de movimento, criatividade. O vocábulo "elance", mais um neologismo criado por Lobato, é formado a partir do verbo "élancer" que significa "se lancer en avant impétueusement" (Petit Robert) e implica uma intuição, uma espécie de insight dificilmente explicável por ser inato ao escritor.

Espaço da crítica Na correspondência enviada a Godofredo Rangel, encontramos também o Lobato crítico informal de literatura. Embora tenha deixado inúmeros prefácios, não podemos falar em crítica de forma sistemática; as páginas de A Barca de Gleyre, porém, atestam sua acuidade nessa área.

Mesmo numa leitura superficial, percebemos como o futuro editor julga as obras a partir de critérios precisos. Diante de um texto novo, Lobato colocava em relevo o tipo de linguagem (preciosa, científica, coloquial), a capacidade de concisão do autor, o poder de sugestão das palavras e a sonoridade das frases. Opinar sobre uma obra significava reconhecer-lhe aspectos linguísticos específicos que nos remetam à filiação estética do autor (embora para ele não fosse o primordial), às suas convicções filosóficas, aos seus preconceitos, enfim, ao que de forma genérica costumamos chamar de "visão de mundo". Se a arte não admitia uma definição, a crítica, por outro lado, necessitava de um método e jamais poderia confundir-se com uma atitude tão-só subjetiva.

Edgar Cavalheiro assinala que Lobato, aos 21 anos, analisou $A$ todo transe, romance inexpressivo de Emanuel Guimarães, num artigo pontual e seguro. O jovem crítico salientou o conceito de vida e a questão da nacionalidade veiculados na obra, além de fazer um paralelo entre o estilo de Guimarães e o de outros romancistas. ${ }^{6}$ Cavalheiro compara o texto do jovem crítico ao de José Veríssimo sobre o mesmo assunto.?

6 Cf. LOBATO, Monteiro. Literatura do Minarete. São Paulo: Brasiliense, 1969, p. 109-13.

7 Trata-se do artigo "Um romance da vida pública brasileira", de José Veríssimo, publicado no vol. V dos Estudos de literatura brasileira. Belo Horizonte: Itatiaia, 1977, p. 55-62

138 - BEDÊ, Ana Luiza Reis. Os intermúndios literários de Monteiro Lobato... 
Os companheiros do "Cenáculo" conheciam a vocação de Lobato para a crítica, não era por acaso que o chamavam de magister dixit. Godofredo Rangel não se furtava a solicitar a opinião do amigo. Em 2 de junho de 1904, Lobato responde em tom irreverente:

Que crueldade a tua, Rangel, com essa mania de explorar o meu magisterdixismo! Queres agora que eu diga de Byron... Que diga o que penso... Byron era como nós, Rangel, mais bonito, aristocrata, com muito dinheiro e coxo.

O futuro criador de Jeca Tatu se insurgia contra a artificialidade da linguagem dos jornais, chegava a calcular a porcentagem do emprego de adjetivos e comparava com as páginas de Camilo Castelo Branco e Euclides da Cunha. Antecipa, assim, em muitos anos, uma das aspirações dos modernistas, que era a valorização do substantivo. Nos grandes escritores o adjetivo é escasso; como exemplo, cita em carta de 19 de agosto de 1905:

Shakespeare, quando quer pintar um cenário (um maravilhoso cenário shakespiriano!), diz, seco: "Uma rua". O Macuco diria: "Uma rua estreita, clara, poeirenta, movimentada, etc." O Macuco espalhou mais adjetivos pelo Belenzinho do que gonococus e nunca houve uma espingarda que o abatesse!

A curiosidade literária de Lobato, já percebemos, estendia-se também ao teatro, às memórias, às crônicas e às correspondências. Graças à influência de Ricardo Gonçalves, seu grande amigo e uma das pessoas a quem Lobato dedica $A$ Barca de Gleyre, passou a gostar também de poesia.

Conhecia bem Camões, lera Vicente de Carvalho, Olavo Bilac e Alberto de Oliveira, a quem fazia sérias restrições. Em 08 de julho de 1917, conta a Rangel sua descoberta, no campo da poesia:

Mas vem surgindo um Guilherme de Almeida, cujo Nós revela muita coisa. Parece-me poeta de verdade - não apenas um burilador de versos como o F., ou parnasiano de miolo mole, essas venerandas relíquias do passado, Alberto, etc. E Bilac, que era a salvaçāo, deu agora para rimar filosofia alheia e fazer patriotismo fardado. Alberto está um perfeito vieux beau. 
Laboratório da criação Hoje, qualquer estudo sobre o intelectual ou o escritor Monteiro Lobato requer uma assídua visita à sua correspondência com Godofredo Rangel. Trata-se de uma via de acesso à sua obra, pois, nas missivas, conhecemos a gênese dos contos "Os faroleiros", "A vingança da peroba", "Bocatorta", "Colcha de retalhos", "O engraçado arrependido", "Pollice Verso", "O matapau", "O estigma", "O comprador de fazendas". Nessas cartas descobrimos o que motivou Lobato a criar a personagem Jeca Tatu, o "piolho da terra", imortalizado no artigo "Velha praga". Além disso, as cartas historiam vários livros idealizados por Lobato, alguns em parceria com seu correspondente.

Há inúmeras referências à sua curta mas fecunda "carreira" de crítico de artes plásticas, à passagem pelos diários interioranos Minarete, O Combatente, O Taubateano, O Povo (de Caçapava), Jornal de Taubaté, pelos conhecidos Correio Paulistano, Gazeta de Notícias, O Estado de S. Paulo e A Tribuna de Santos, além da colaboração em Fon-Fon, A Cigarra, Vida Moderna e O Pirralho.

Nas missivas, podemos igualmente acompanhar o nascimento da Revista do Brasil em 1916 e as circunstâncias em que Monteiro Lobato assumiu sua direção em maio de 1918, assim como a criação da Empresa Editora "Revista do Brasil" Ficamos conhecendo como foi a sua recepção no mercado argentino em 1919, os progressos da empresa e posterior falência, em 1925.

Ana Luiza Reis Bedê é doutora em Literatura Francesa pela Universidade de São Paulo e autora de Monteiro Lobato e a presença francesa em A barca de Gleyre [Annablume/ Fapesp, 2007]. 